\title{
1 Height differences in clonal stands of Tussilago farfara promote outcrossing by influencing
}

\section{2 pollinator behaviour}

3 Aleksandra J. Dolezal

4 Department of Integrative Biology, University of Guelph, Guelph, Ontario, Canada

5 Correspondence to: adolezal@uoguelph.ca

6 ORCiD: 0000-0002-1388-3610

\section{Abstract}

8 Plants with mixed mating systems balance the advantages of selfing and the costs of inbreeding.

9 Previous studies have shown that plant species with the ability to self-pollinate and cross

10 pollinate have strategies to promote outcrossing to increase genetic diversity. Various features of

11 floral morphology are thought to be deliberate mechanisms to manipulate plant mating systems. I

12 hypothesized that within-plant variation in flower stem height is a morphological trait that can

13 reduce geitonogamy by increasing pollinator movement among plants. This hypothesis was

14 tested using coltsfoot (Tussilago farfara); coltsfoot plants host several flowering stems that differ

15 in height, with each stem having a single, terminal flowerhead. I used cut flowers to create

16 'populations' of coltsfoot in which each plant had four inflorescences with equal or unequal

17 flower stalk lengths and measured frequency of insect pollinators that would stay among flowers

18 within a plant or move to other plants. All pollinators (bee flies, hover flies, solitary bees and

19 wasps) showed a marked discrimination in favor of leaving plants with flowers of different

20 heights and stayed when plants had flowers of the same height. This study shows that variation

21 in flower heights is important for reducing geitonogamy in coltsfoot and suggests that the

22 evolution of this morphological trait should be considered in studies of mating systems.

23 Keywords: Insect behaviour, outcrossing, mixed mating system, plant height, Tussilago farfara 


\section{Introduction}

One of the fundamental questions in ecology is how plant morphology affects pollinator behavior (Chaffey, 2014). In particular, how does plant morphology indirectly affect reproductive strategy when a species can both self-pollinate and cross-pollinate? Many plants in nature employ mixed mating strategies to better increase their chances of becoming fertilized and to increase seed set (Pannell et al., 2013). However, a reproductive strategy to promote outcrossing is of critical importance for the adaptation and evolution of all eukaryotic organisms (Raven et al., 2005).

Plants have methods to reduce or avoid geitonogamy in order to increase the amount of genetic variation within and among populations (Loveless and Hamrick, 1984). Separate male and female flowers may both occur on the same plant or occur at separate times when they each reach maturity during different periods in monoecious plants, however some plants produce staminate and pistilate flowers on separate plants (Raven et al., 2005). This strategy occurs in dioecious plants where flowers are constructed such that stamens and stigmas never meet each other to rely exclusively on outcrossing. In this extreme case, pollen must be transferred to the stigma of another flower rather than itself which never allows self-pollination to occur. In recent years, studies have looked at the relative importance of plant traits on pollinator visitation rate and the role that these floral morphological traits have on the fitness of the plant species. If a plant is multiflowered, this may be important to attract pollinators by having a big enough display, but there is a risk that a flower visitor will go from one flower to another on the same individual, thus increasing geitonogamy (Wilmer, 2011). Understanding how foraging choices occur at the local scale is essential because these choices may directly affect plant fitness (Lazaro and Totland, 2010). Many different processes are involved in explaining plant 
47 morphological traits into realized success for insect pollinated plants, such as the effects of plant

48 traits directly on the behavior of insect pollinators (Mitchell, 1994). For example, pollinator

49 visitation rates differ among plant species due to the response to traits such as floral size, floral

50 shape, color preference, and the rate of nectar production (Mitchell and Waser, 1992; Campbell,

51 1991). However, little is known about local foraging decisions for the majority of pollinator

52 guilds, with the exception of bumblebees (Stout et al., 1998).

Several studies have investigated the effects of plant morphological traits in manipulating

54 pollinator behavior and mating cost in hermaphroditic species. For example, Harder and Barrett

55 (1995) found that large floral displays of Eichhornia paniculata had enhanced pollinator

attraction, however endured higher selfing and lower outcrossing rates due to pollen discounting

57 by bees. Similarly, Williams et al. (2001) investigated a different morphological trait, the number

58 of inflorescences per plant, and showed that distinct plants with multiple inflorescences attract

59 more pollinators than those with single inflorescences. In the context of plant fitness, increased

60 visitation to plants with multiple inflorescences may also reduce the fraction of selfed seeds

61 (Miyake and Sakai, 2005), due to the greater import of pollen from other plants. Overall, this

62 research highlights that a number of plant morphological traits influence pollinator behavior and

63 affects mating costs in self-compatible species.

64 Although studies have illustrated how several morphological traits alter pollinator

65 movements and outcrossing rates, some traits, such as flower height, remain less understood.

66 Previous studies of selection for floral traits indicate plant height as an important trait for

67 pollination success (Johnston 1991). Lortie and Aarssen (1999) found that taller plants of the

68 biennial weed Verbascum thapsus attracted more pollinators, showing that they may experience

69 higher rates of outcrossing and have more diverse pollen donor arrays. Hingston and Potts (2005) 
70 found that the gum tree Eucalyptus globulus had higher outcrossing rates on its upper branches

71 due to the flowers occurring at different heights. This resulted in birds foraging more in the

72 upper canopy region. Height variation of flowers may attract different types of visitors, or

73 different visitation rates of these individual visitors (Wilmer, 2011). Many species of plants

74 present flowers at multiple heights, in some cases this variation in flower height may be due to

75 architectural constraints of the plant, in others, however, there is no clear reason for this variation

76 in flower height. For example, coltsfoot (Tussilago farfara, Asteraceae) has terminal flowerheads

77 on stalks that emerge from the soil and differ in height. Nonetheless, these stalks typically grow

78 longer and more uniform post-fertilization and prior to seed release, suggesting that resources or

79 architectural constraints do not drive intraspecific variation (Bakker, 1960). As a result, it is

80 unclear why this height variation and height constancy persists in this species.

87 or leave clonal stands in each treatment. To my knowledge, this is the first study to determine the effect of different flower heights on pollinator preference and geitonogamy. 
92 clonal stands? (iii) Do different types of T. farfara flower visitors (bee flies, hover flies, solitary

93 bees, and wasps) respond differently to within-plant variation in flower height?

\section{Methods}

95 Study species

Tussilago farfara is a small, clonal, herbaceous perennial in the Asteraceae family. It has

97 been introduced to North America and has a wide distribution throughout the continent

98 (Myerscough and Whitehead, 1996). It is commonly found in clusters of multiple height stems (5

$99 \mathrm{~cm}-30 \mathrm{~cm}$ ) produced by a single rosette, with hermaphroditic flowers. The flowers appear early

100 in spring, prior to the emergence of any leaves when increasing temperatures initiate elongation

101 of the inflorescence stems followed by flowering (Balchin and Pye, 1950). The golden-yellow

102 flower heads contain an outer region of numerous female ray florets and inner region of 30-40

103 male disc florets (Pfeiffer et al., 2008). The flower heads are protogynous, in which the female

104 reproductive organs mature before the male reproductive organs (Myerscough and Whitehead,

105 1996). This species has a mixed mating system, and can both self-pollinate and outcross. A study

106 on the reproductive strategy of Tussilago farfara by Ogden (1974) found that, in dense

107 populations, vegetative reproduction fails, and seed production suffers little. Reproductive tactics

108 tend to favor seed production relative to clonal spread. At the study site, it is mainly visited by

109 hover flies, bee flies, and solitary bees, but wasps were observed and also included in this study.

110 Study area

111 Field work for this study was conducted from May 10 to May 13, 2016 with a population

112 of T. farfara located at Koffler Science Reserve at Jokers Hill (King township, Ont.; 4403N, 
$\left.11379^{\circ} 53^{\prime} \mathrm{W}\right)$. Samples were taken from three populations located within $1 \mathrm{~km}$ of each other. All

114 sites were in partial to full sun and were along roadsides or trail sides in areas that are regularly

115 disturbed by mowing.

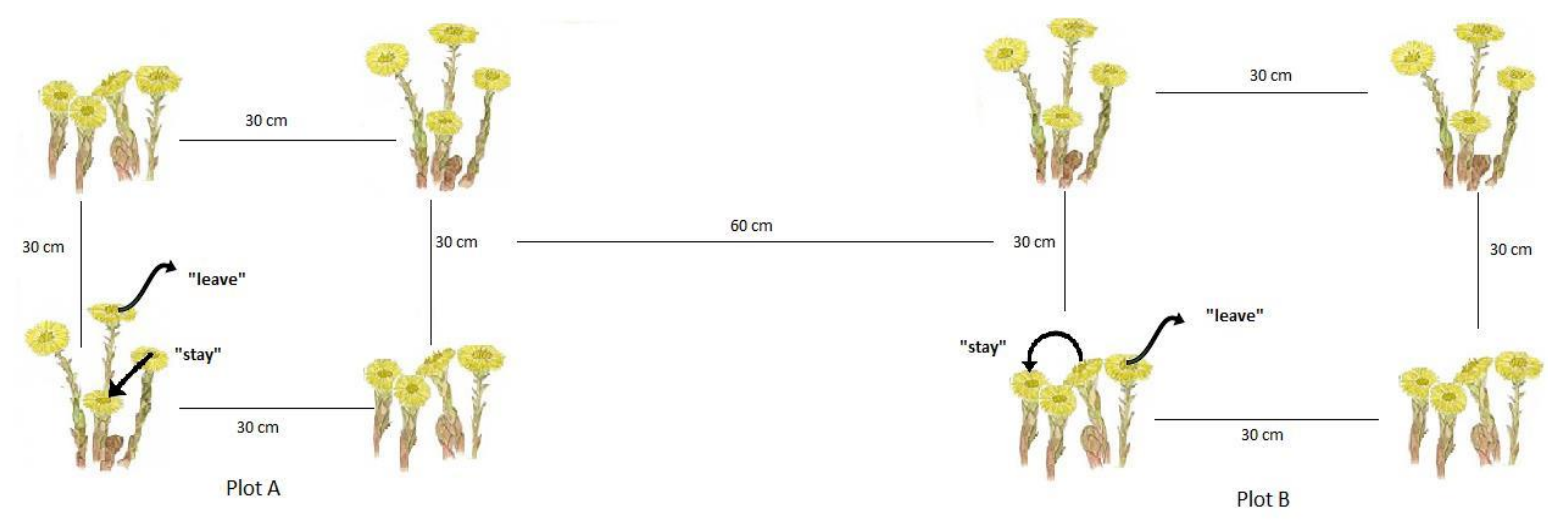

117 Figure 1: Experimental design consisting of two treatments: different height (DH) and same

118 height (SH). Plot A and Plot B include a combination of two DH and two SH treatments, A has

119 vials diagonally across from each other and B has treatments parallel to each other. A

120 pollinator's action was considered "leave" if it landed on a flower and its next decision was to fly

121 away or fly to another clonal stand. An action was considered "stay" if a pollinator's next

122 decision was to land on any of the four flowers within the clonal stand.

125 I designed two treatments to determine whether variation in stem height would alter 126 pollinator behavior. The two treatments consisted of a different height treatment with stem heights

127 consisting of $6 \mathrm{~cm}, 10 \mathrm{~cm}, 14 \mathrm{~cm}$, and $18 \mathrm{~cm}$ and a same height treatment consisting of four flowers

128 all $12 \mathrm{~cm}$. These heights were chosen to reflect natural variation in flower stem length, the mean

129 length of $T$. farfara in the study sites being $12 \mathrm{~cm}$. Flowers were cut at the start of the day when 
130 they were open, and flowers of a similar size and age were chosen to make sure there was no bias

131 from pollinators to visit stands of different flowers.

In each experimental unit, I cut and manipulated stems of four flowers to be placed into a

vial. Each of these experimental units consisted of four flowers in a vial with soil from the study

134 site and water to keep plants from wilting during observations. Two experimental units were placed

$13530 \mathrm{~cm}$ apart (the average distance observed in natural populations) from each other in a single

136 block, and treatments within a block contained two replicates of each treatment (Figure 1). These

137 different treatment combinations were used to ensure pollinator behavior is not influenced by

138 nearby flowers.

139 Data collection

140 During May 11 to May 13, plants were observed for insect pollinators. All observations

141 were conducted in sunny stands starting at 11:30 am - 1:30 am unless wind or rain disrupted

142 foraging behavior, then different times of the day were chosen to accommodate optimal sun

143 exposure. I observed each treatment plot for insect pollinators for two hours. Pollinators were

144 observed approximately $2 \mathrm{~m}$ away from plots using binoculars. Pollinators did not appear to alter

145 foraging behavior in response to my proximity. A visit was defined to have occurred when the

146 visitor's body contacted the reproductive organs (ray or disc florets) of the flower. The insects'

147 next decision was observed and recorded; moving to another flower in the same vial was

148 recorded as 'staying', whereas moving to another flower in a different vial was recorded as

149 'leaving'. Once a pollinator was recorded as staying or leaving, no further observations were

150 made for that pollinator during that visit (because the individual pollinators were not marked,

151 repeat visits by individual pollinators over several hours or days may have occurred). I

152 categorized visitors to one of four groups: bee flies, hover flies, solitary bees and wasps. Each 
153 plot was located near a stand of T. farfara to get the same pollinator groups. T. farfara was

154 chosen because they are common at Koffler Scientific Reserve and were in bloom early May. No

155 other plant species bloomed in the study areas except for dandelions which have similar

156 pollinators as the study species.

157 Statistical analysis

158 I used a Pearson's Chi-squared test with Yates' continuity correction via RStudio

159 (RStudio, 2015), to examine the effects of plant height on pollinator visitation behavior. The

160 response variable was the leave/stay $(0 / 1)$ action observed in each treatment. In this analysis,

161 data from all three sites were pooled to increase sample size and because the results did not differ

162 between sites (results not shown). Fishers Exact Test was used to obtain p-values for pooled

163 samples.

\section{Results}

A total of 190 pollinators were observed May 11 to May 13, 2015. The relative

abundance of four pollinator types varied across populations (Figure 3) and both solitary bees

167 and hover flies were the dominant visitors to T. farfara stands. Neither treatment nor any

168 interaction effects of treatments had an effect on insect visitation rates - there was no significant

169 difference in the frequency of pollinators that visited the 'different height' treatment (94/190)

170 compared to the 'same height' treatment (96/190; Figure 2, $\left.\mathrm{x}^{2}=0.0046, \mathrm{DF}=1, \mathrm{P}=0.9458\right)$. These

171 results indicate that there was no preference for one type of treatment.

172 The height difference treatment has a significant effect on pollinator behavior. When

173 inflorescences were presented at different height, insects were more prone to leave a stand of

174 flowers, whereas they were more likely to stay and forage within a stand when inflorescences 
175 were presented at the same height (Figure $\left.2 ; \mathrm{x}^{2}=63.042, \mathrm{DF}=1, \mathrm{p}<0.001\right)$. This behavior of

176 pollinators suggests that geitonogamy will be reduced in T.farfara when inflorescences differ in

177 height, as pollinators are more likely to visit flowers of other plants.

178

179 Figure 2: Frequency of pollinator visitations to $T$. farfara occurring in plots with different

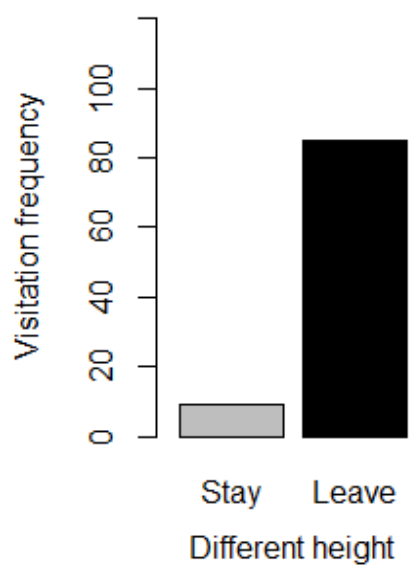

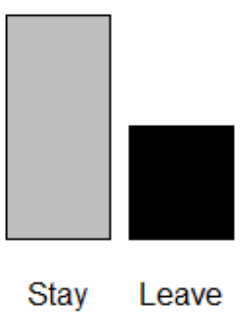

Same height

treatments in three study populations $(\mathrm{n}($ different height $)=94, \mathrm{n}($ same height $)=96))$.

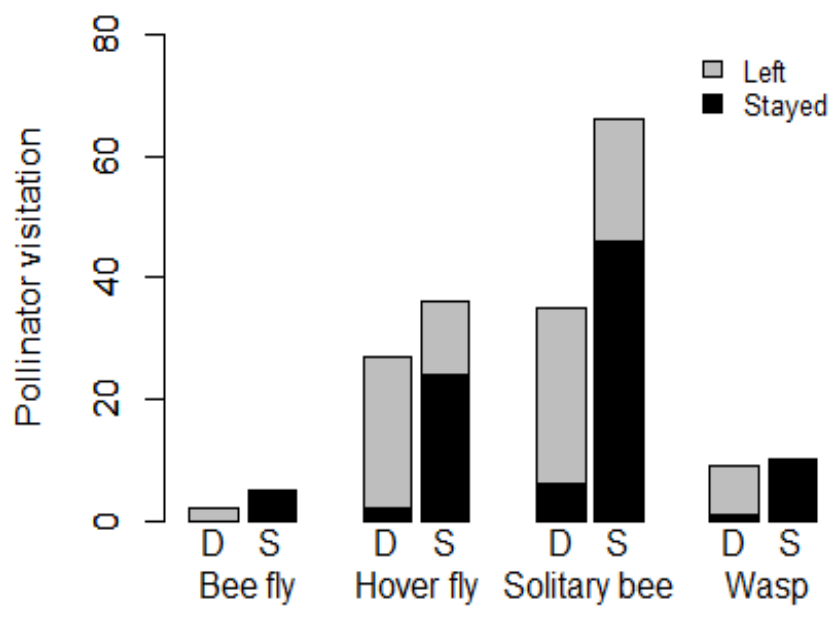

182 Figure 3: Pollinator visitation behavior occurring in height treatments of T. farfara plots. P-

183 values are based on Fisher's Exact Test. No difference between pollinator behaviors in

184 treatments (D represents different height treatment and S represents same height treatment). Grey

185 and black colors represent the action of leaving a stand or staying within a stand, respectively. 

general trend of leaving treatments of different height flowers and staying within treatments of same height flowers. The bee fly showed the most significant trend, in which it always left a different height stand and always stayed within a same height stand $(\mathrm{N}=7, \mathrm{p}<0.05)$. Other pollinators include: hover fly $(\mathrm{N}=63, \mathrm{p}<0.001)$, solitary bee $(\mathrm{N}=101, \mathrm{p}<0.001)$ and wasp $(\mathrm{N}=19$, $191 \mathrm{p}<0.001)$.

\section{Discussion}

In this study, I have demonstrated that height variation affects pollinator behavior and

194 consequent reproductive strategy in populations of T. farfara. Generally, pollinators that landed within a different height treatment left the clonal stand and those that landed on a same height treatment stayed within a clonal stand. My data suggests that even though there are a variety of

197 pollinators visiting flowers (Figure 3), they all exhibit the same behavior: leaving different height

198 flowers and staying within same height flowers (Figure 3). My findings support the hypothesis that hermaphroditic plant morphology in T. farfara promotes outcrossing with the use of height variation to manipulate insect pollinators. This study is the first to document that natural height

201 variation in T. farfara influences pollinator behavior and promotes outcrossing. Due to the fact

202 that my results are based on observations of flowers under natural conditions, they could

203 potentially support the association of flower stem height variation and reduced geitonogamy in 204 other taxa of the Asteraceae family. 
grid treatments there may have been times when I was viewing one stand and pollinators came into the other that I did not record. For a future study, perhaps another observer could assist me

211 in recording data. Second, two days of observations were cloudy and had $45 \mathrm{~km} / \mathrm{h}$ wind that

212 offered a limited window to observe pollinators. Pollinator flight activity is constrained by severe

213 weather conditions (Totland and Matthews, 1998) such as wind speed or temperature which

214 could influence pollinators to forage differently. Third, depletion of nectar resource from disc

215 rays of the flower could have influenced more pollinators to leave clonal stands if they

216 experienced a no-nectar flower within that stand. Studies have suggested that a pollinator

217 (specifically bees) leaves a plant if it comes across one or two nectar-poor flowers (Kadmon and

218 Shmida, 1992). Studies of bumble bees determine that they visit other flowers on individual

219 inflorescences if those flowers provide nectar reward (Cresswell, 1990; Johnson et al., 2004) and

220 if the costs of foraging for previously unvisited flowers remain fairly small (Ishii et al., 2008). A

221 pollinator should leave an unrewarding plant as soon as possible but stay and continue to visit the

222 flowers on a rewarding plant. It would be worthwhile to test the pollinators of $T$. farfara to see if

223 they show similar behaviors in foraging when nectar is added to flowers. Fourth, the flower

224 orientation could have influenced pollinator behavior in leaving or staying within stands. The

225 different height treatment flowers were at angles because of the weight of the taller stems

226 inching forward, while the same height flowers stood upright in the same horizontal positions.

227 Floral orientation is thought to affect pollinator attraction, foraging behavior, and pollen transfer

228 (Wang et al., 2014). However, previous studies are on species of plants that produce single

229 flowers, and rather little is known about the effect of floral orientation on pollination in more

230 multifaceted inflorescences. Future research is necessary to examine the effect of flower

231 orientation on pollen import and export, as well as the visitation behavior of pollinators, in order 
232 to understand the influences that horizontal orientation or vertical orientation may have on

233 outcrossing success.

Future research should investigate whether this pollinator behavior indeed increases plant

235 fitness and how flower stem height affects probing times. Carromro and Hamrick (2005) in their

236 study of Verbascum thapsus demonstrated that tall plants receive larger and more genetically

237 diverse pollen loads, while shorter plants experience pollen limitation which lead to increased

238 selfing. However, similar to my study, the authors did not look at times spent on flowers of

239 different heights which could also affect plant fitness. During my observations I noticed that

240 pollinators seemed to probe disc rays on the same height treatment for longer than on the

241 different height treatments. It would be beneficial to add duration of probing time as another

242 variable in my study to determine how pollinator behavior may be affected. Since pollinators can

243 see that flowers are close by, I would predict they would have fewer probing rates on same

244 height treatments. This is because the costs of searching is not constrained for flowers side by

245 side. Waddington and Holden (1979) proposed that honeybee visitation to flowers is based on an

246 optimal foraging model where a bee achieves maximum caloric intake by choosing to visit the

247 closest flower. It would be worthwhile to see if seed set is higher for treatments with longer

248 probing times, as this would increase individual plant fitness.

A study by Waddington (1979) states that there is greater selection against plants of

250 heights where the probability of interspecific pollinator flights is at its highest, and therefore

251 plant species partition pollinators by presenting inflorescences at different heights. He suggested

252 that pollinators shared by the species exhibited the same horizontal flight pattern, where they

253 tended to remain at a certain height when foraging between flowers. Similarly, I have shown that

254 plants presenting flower heads at different heights would reduce geitonogamy because 
255 pollinators would be more likely to move horizontally rather than vertically. Plant height

256 differences can have a direct effect on pollinator behavior and thus, resulting in an indirect effect

257 on reproduction. Considering the mating costs of geitonogamy, selection should present floral

258 traits that reduce geitonogamy in clonal plants with a clumped architecture, such as limiting

259 same height inflorescences (De Jong et al., 1992). The magnitude of the potential fitness

260 consequences associated with geitonogamy in $T$. farfara and how they are balanced by the

261 reproductive benefits of flower height display are currently unknown. Species with mixed mating

262 strategies present unique opportunities for understanding the evolution of mating systems. In the

263 case of T.farfara, it is further complicated by the indirect effect that inflorescent height has on

264 promoting outcrossing rates by manipulating foraging decisions in insect pollinators. 
265 Acknowledgements: I thank J. Eckenwalder and B. Gilbert for valuable comments on early

266 versions of this experiment and in all aspects of this work. I thank A. Korda for assistance in the

267 field and in harvesting flower stems. I thank S. Wadgymar with assistance in statistical analyses. 


\section{References}

Bakker, D. 1960. A comparative life-history study of Cirsium arvense (L.) Scop, and Tussilago farfara L., the most troublesome weeds in the newly reclaimed polders of the former Zuiderzee. - In: Harper, J. L. (Ed.), The biology of weeds. Oxford: Blackwell Scientific Publishers, pp. 205-222.

Balchin, W.G.V., and Pye, N. 1950. Observations on local temperature variations and plant responses. - J. EcoL. 38: 345-353.

Campbell, D.R. 1991. Effects of floral traits on sequential components of fitness in Ipomopsis aggregata. - Am. Nat. 137: 713-737.

Carromero W., and Hamrick, J.L. 2005. The Mating System of Verbascum thapsus (Scrophulariaceae): The Effect of Plant Height. - Int. J. Plant Sci. 166: 979-983.

Chaffey, N. 2014. Raven biology of plants, 8th Ed. - Ann Bot-London, 113(7), Vii.

Cresswell, J.E. 1990. How and why do nectar-foraging bumblebees initiate movements between inflorescences of wild Monarda fistulosa (Lamiaceae)? - Oecologia 82:450-460.

De Jong T.J. et al. 1993. Geitonogamy: the neglected side of selfing. - Trends Ecol Evolut. 8: 321-325.

Faegri K., and Pijl, L. 1979. The principles of pollination ecology (3rd rev. ed. ed., Pergamon international library of Science, technology, engineering, and social studies). - Oxford: Pergamon Press.

Harder, L.D., and Barrett, S.C.H. 1995. Mating cost of large floral displays in hermaphrodite plants. - Nature 373: 512-515 
Hingston, A.B., and Potts, B.M. 2005. Pollinator activity can explain variation in outcrossing rates within individual trees. - Aust Ecol. 30: 319-24.

Ishii, H.S. et al. 2008. Combined effects of inflorescence architecture, display size, plant density and empty flowers on bumble bee behavior: experimental study with artificial inflorescences. - Oecologia 156:341-350.

Johnson, S.D. et al. 2004. The effects of nectar addition on pollen removal and geitonogamy in the non-rewarding orchid Anacamptis morio. - Proc. R. Soc. B. 271: 803-809.

Johnston M.O. 1991. Natural selection on floral traits in two species of Lobelia with different pollinators. - Evolution 45: 1468-1479.

Kadmon, R., and Shmida, A. 1992. Departure rules used by bees foraging for nectar: a field test. - Evol. Ecol. 6: 142-151.

Lazaro, A., and Totland, O. 2010. Local floral composition and the behavior of pollinators: Attraction to and foraging within experimental patches. - Ecol. Entomol. 35: 652-661.

Lortie, C.J, and Aarssen, L.W. 1999. The advantage of being tall: higher flowers receive more pollen in Verbascum thapsus L. (Scrophulariaceae). - Ecoscience 6: 68-71.

Loveless M.D., and Hamrick, J.L. 1984. Ecological determinants of genetic structure in plant populations. - Annu. Rev. Ecol. Syst. 15: 65-95.

Mitchell, R. J., and Waser, N. M. 1992. Adaptive significance of Ipomopsis aggregata nectar production: pollination success of single flowers. - Ecology 73:633-638.

Mitchell, R.J. 1994. Effects of floral traits, pollinator visitation, and plant size on Ipomopsis aggregata fruit production. - Am. Nat. 143: 870-889. 
Miyake, Y.C., and Sakai, S. 2005. Effects of number of flowers per raceme and number of racemes per plant on bumblebee visits and female reproductive success in Salvia nipponica (Labiatae). - Ecol. Res. 20: 395-403.

Myerscough, P.J., and Whitehead, F.H. 1996. Comparative Biology of Tussilago farfara L., Chamaenerion angustifolium (L.) Scop. Epilobium montanum L., and Epilobium adenocaulon Hausskn. I. General Biology and Germination. - New Phytol. 65: 192-210.

Ogden, J. 1974. The Reproductive Strategy of Higher Plants: II. The Reproductive Strategy of Tussilago Farfara L. - J. Ecol. 62: 291-324.

Pannell, J.R., and Labouche, A.M. 2013. The incidence and selection of multiple mating in plants. - Philos. Trans. Royal Soc. B. 368: 20120051.

Pfeiffer, T. et al. 2008. Clonal reproduction, vegetative multiplication and habitat colonisation in Tussilago farfara (Asteraceae): A combined morpho-ecological and molecular study. Flora. 203: 281-291.

Raven, P. et al. 2005. Plant Reproduction. - In Biology of plants (7th ed.). New York, NY: W.H. Freeman, pp. 837-850.

RStudio. 2015. RStudio: Integrated development environment for R (Version 98.1103) [Computer software]. Boston, MA. Retrieved May 14, 2015.

Stout, J.C. et al. 1998. The influence of relative plant density and floral morphological complexity on the behavior of bumblebees. - Oecologia, 117: 543-550.

Totland, O. and Matthews, I. 1998. Determinants of pollinator activity and flower preference in the early spring blooming Crocus vernus. Acta Oecologica 19: 155-165. 
331 Waddington, K.D, and Holden, L.R. 1979. Optimal foraging: On flower selection by bees. - Am. Nat. 114: 179-196.

333 Waddington, K.D. 1979. Divergence in inflorescence height: An evolutionary response to pollinator fidelity. - Oecologica. 40: 43-50.

335 Wang, H. et al. 2014. Change of floral orientation within an inflorescence affects pollinator behavior and pollination efficiency in a bee-pollinated plant, Corydalis sheareri. - PLOS One 9: e95381.

Williams, C. F. et al. 2001. Pollination, breeding systems, and genetic structure in two sympatric Delphinium (Ranunculaceae) species. - Am. J. Bot. 88: 1623-1633.

340 Wilmer, P. 2011. Pollination, mating, and reproduction in plants. - In Pollination and Floral Ecology Princeton University Press. pp. 55-87. 